\title{
A influência da presença de ar na micromedição em redes de abastecimento
}

\author{
The influence of air presence on flow measurement related to water supply system
} William Alves Tavares ${ }^{1 *} \odot$, Elson Antonio do Nascimento ${ }^{1} \odot$, Gabriel de Carvalho Nascimento ${ }^{1}$

口-

\section{RESUMO}

Em redes de abastecimento de água, as manobras de válvulas e as paradas de bombas, por exemplo, podem causar a entrada de ar nas tubulações, sendo este ar, em algumas situações, eliminado através das ligações domiciliares, com potencial de majorar os volumes registrados pelos hidrômetros. Esse tem sido motivo de preocupação por parte de órgãos fiscalizadores, de concessionárias e de consumidores, principalmente, em grandes cidades brasileiras. A despeito da grande importância do assunto, observa-se que há uma quantidade ainda pequena de estudos e trabalhos técnico-científicos sobre este tema. A presente pesquisa teve como objetivo apresentar parâmetros e procedimentos que auxiliem o entendimento do funcionamento de hidrômetros sob presença de ar e a consequente influência nos volumes registrados. Um método simples e eficaz foi elaborado para realização de testes em bancada que possibilitaram quantificar o volume de ar escoado que é, efetivamente, registrado por um hidrômetro deuso típico em ligações residenciais. Os resultados mostram que os hidrômetros podem registrar até $90 \%$ do volume de ar eventualmente escoado, quando as vazões são elevadas, em torno de 1.600 L/h. Em baixas vazões, esse percentual cai, tornando-se nulo quando a vazão é inferior a $430 \mathrm{~L} / \mathrm{h}$. No casso de inversão de fluxo no hidrômetro, o que ocorre durante o esvaziamento da rede, os valores registrados são menores que aqueles medidos quando o fluxo ocorre no sentido nominal, não compensando, integralmente, os eventuais volumes de ar contabilizados durante o enchimento.

Palavras-chave: abastecimento de água; ar em tubulações; micromedições.

\begin{abstract}
In water supply networks, valve maneuvers and pump stop, for example, can cause air to enter the pipelines and, in some situations, this air can be eliminated through home connections, with the potential to increase registered volumes by the water meters. This has been a cause for concern by the part of inspection agencies, concessionaires and consumers, mainly in large Brazilian cities. Despite the great importance of the subject, it is observed that there is still a small amount of studies and technical-scientific works on this subject. The present research had as objective to present parameters and procedures that help the understanding of the operation of water meters under the presence of air and the consequent influence on the recorded volumes. A simple and effective method was developed to perform bench tests that made it possible to quantify the volume of air flow that is effectively recorded by a water meter typically used in residential connections. The results show that the volume of air registered in the water meters can reach values up to $90 \%$, when the flow rates are high, around 1,600 L/h. At low flow rates, this percentages drops, becoming null when the flow rates are less than $430 \mathrm{~L} / \mathrm{h}$. In case of flow inversion occurring in the water meter, the recorded values are smaller than those measured when the flow occurs in the nominal sense, not fully compensating the possible volumes of air accounted for during the water supply.
\end{abstract}

Keywords: water supply; air in pipes; micro-measurements.

\section{INTRODUÇÃO}

Segundo Fonseca e Prado Filho (2008), a partir de meados do século XIX, no Brasil, o critério estabelecido pelo poder público para o fornecimento de água a particulares era a utilização da denominada pena d’água. A cobrança de água, através do uso desse instrumento, era baseada apenas nas dimensões da seção circular das tubulações que chegavam às residências, não levando em conta a vazão ou o volume de água consumida. Somente cerca de cem anos depois, em 1968, de acordo com a Companhia Estadual de Águas e Esgotos do Rio de Janeiro (CEDAE, 2018), é que a cobrança de água passou a ser feita por meio da utilização de hidrômetros nos sistemas de abastecimento, tendo como base o volume de água registrado por esses equipamentos.

Em tempos de crise hídrica e econômica, o consumo de água tem despertado uma maior atenção por parte dos consumidores e das autoridades. Segundo a Lei Federal $\mathrm{n}^{\circ}$ 9.433, de 8 de janeiro de 1997 (BRASIL, 1997), a água é um recurso natural limitado e dotado de valor econômico. A partir dessa data, também a captação de água nos mananciais, rios, lagos e aquíferos passou a ser cobrada com reflexos no custo final da água tratada e distribuída para a população. Portanto, em todo o sistema de abastecimento deágua, seu uso deve ser racional, evitando-se desperdícios e cobranças indevidas.

口

'Universidade Federal Fluminense - Niterói (RJ), Brasil.

*Autor correspondente: williamtavares@id.uff.br

Conflitos de interesse: os autores declaram não haver conflito de interesses.

Fonte de financiamento: Coordenação de Aperfeiçoamento de Pessoal de Nível Superior (CAPES) - Código de Financiamento O01.

Recebido: 2O/O8/2O19 - Aceito: O2/O3/2O2O - Reg. ABES: 20190288 
Um sistema de abastecimento de água é o conjunto de tubulações, acessórios, reservatórios e bombas, que tem a finalidade de atender, dentro de condições sanitárias, de vazão e pressão convenientes, a cada um dos diversos pontos de consumo de uma cidade ou setor de abastecimento (PORTO, 2006). No fornecimento de água aos consumidores, é feita a medição de consumo através dos hidrômetros. A instalação desses dispositivos é requisito indispensável para uma cobrança de valor justo para a água consumida, além de ser fator importante para evitar um gasto excessivo (MACINTYRE, 2013).

Um dos problemas que podem ocorrer no abastecimento de água é a submedição, ou seja, a contabilização pelo hidrômetro de um volume de água inferior ao que efetivamente foi consumido. Sanchez, Motta e Alves (2000), através de trabalho de campo na cidade de Juazeiro, Bahia, observaram que a submedição acontece, principalmente, nos casos em que o fornecimento de água ocorre em baixas vazões, inferiores à mínima especificada (NBR 212:1999). Essa observação foi corroborada, posteriormente, por Pereira e Ilha (2008), por meio de um estudo na cidade de Campinas, São Paulo. Por outro lado, é possível que outros problemas ocasionem o efeito inverso, ou seja, uma sobremedição, caracterizada pela contabilização de um volume superior ao efetivamente consumido.

Para Mello e Farias (2001, p. 1), "a presença do ar em canalizações, que aduzem ou transportam líquidos, é um fenômeno previsível sob o ponto de vista hidráulico". Sendo assim, uma dúvida que surge por parte de consumidores é se o volume de ar presente nas tubulações de água flui pelos hidrômetros e é por estes registrado, em condições de causar um acréscimo significativo no valor total medido. Os hidrômetros são instrumentos instalados na rede com o propósito de medir o volume de água. Entretanto, em razão de não fazerem distinção entre os fluidos que passam por eles, podem também medir, conjuntamente, eventuais volumes de ar.

Ressalta-se ainda que as redes de distribuição de água são frequentemente submetidas a manobras que resultam no enchimento e esvaziamento das tubulações. Com isso, os fluidos, ar ou água, que passam pelos hidrômetros também têm seus sentidos de escoamento alternados. Quando ocorre enchimento da rede, o escoamento se dá no sentido nominal (projetado) de funcionamento do hidrômetro e, consequentemente, por ocasião do esvaziamento da rede, o escoamento se dá no sentido inverso. Scalize e Leite (2013) analisaram o comportamento do hidrômetro perante escoamento de água em ambos os sentidos. Constataram que, quando o escoamento ocorre no sentido inverso, o volume de água contabilizado é menor que o volume de água escoado no sentido nominal. Com isso, nas situações de esvaziamentos e enchimentos de rede, a variação do volume de água contabilizado no hidrômetro pode resultar numa sobremedição.

Além da variação no sentido de fluxo de água, podem existir outras causas para o erro de medição dos hidrômetros, como, por exemplo, fluxo de ar e fluxo bifásico (água e ar). Tavares, Nascimento e Nascimento (2018), através de um trabalho de campo, monitoraram uma ligação residencial de fornecimento de água. Por meio de um aparato formado por dois hidrômetros e uma válvula ventosa posicionada entre eles, puderam constatar que um volume de, aproximadamente, $40 \mathrm{~m}^{3}$ de ar escoou pelo ponto avaliado ao longo de 45 dias, contabilizados, quase em sua totalidade, em períodos que precediam a chegada da água, portanto durante o enchimento da rede. Concluíram, consequentemente, que volumes significativos de ar podem, de fato, estar presentes no fornecimento de água e ser registrados pelos hidrômetros.

Por esses motivos, foi considerada, no presente estudo, a verificação do comportamento dos hidrômetros para situações em que haja apenas ar na tubulação (fluxo monofásico), escoando tanto no sentido nominal quanto no sentido inverso.

Inicialmente, foram feitas aferições dos hidrômetros utilizados, com o intuito de verificar a precisão de cada um. Posteriormente, foram realizadas as medições para o escoamento de ar. Os testes foram executados no Laboratório de Hidráulica da Escola de Engenharia da Universidade Federal Fluminense (HidroUFF).

\section{Presença de ar nas tubulações}

Leal e Teixeira (2001) apontam que, em condições ideais, a presença de ar nas redes de abastecimento de água é desprezível. Porém, extraordinariamente, volumes consideráveis de ar podem entrar no sistema. Segundo Tsutiya (2014), a ocorrência de ar nas tubulações pode ocorrer por diversos fatores, entre eles:

- ar dissolvido oriundo da coleta ou incorporado na estação de tratamento;

- parada de bomba;

- manobra de válvulas;

- baixo nível de água nos reservatórios, ocasionando vórtices na tubulação de saída;

- ressalto hidráulico em trechos da adutora em superfície livre;

- trechos onde ocorre pressão negativa.

O item 5.10.3 da norma NBR 12218/1994 (Projeto de rede de distribuição de água para abastecimento público) da Associação Brasileira de Normas Técnicas (ABNT) cita a instalação de ventosas em locais elevados, com o intuito de evitar pressões negativas na tubulação (ABNT, 1994). Portanto, a entrada de ar na tubulação pode ser intencionalmente provocada em situações de baixa pressão, o que ocorre, por exemplo, pelo desligamento de bombas em caso de interrupção do fornecimento de energia elétrica.

Normalmente, as redes de distribuição são divididas em setores, e o fornecimento é alternado entre eles ao longo dos dias da semana, através da manobra de registros ou válvulas. Dessa maneira, tornam-se frequentes os ciclos de esvaziamento e enchimento das tubulações, que podem promover a entrada $\mathrm{e}$ a saída de ar no sistema, respectivamente.

Quando a rede hidráulica apresenta válvulas ventosas de admissão e de expulsão de ar adequadamente instaladas, $\mathrm{o}$ ar eventualmente contido na tubulação é eliminado integralmente durante o processo de enchimento de água na tubulação principal. No entanto, ocasionalmente, seja por falha de projeto ou em razão da manutenção inadequada das ventosas, o ar não é totalmente eliminado pelas válvulas ventosas de expulsão de ar, podendo ser, então, encaminhado para os pontos de consumo, principalmente em regiões elevadas ou em final de linha. Nesse caso, o ar passará pelos hidrômetros, podendo ser registrado em conjunto com o volume de água efetivamente fornecido. Vale ressaltar que, durante o esvaziamento de um determinado setor, a entrada de ar na rede pode ocorrer pelos próprios pontos de abastecimento, ocasionando fluxo de ar nos hidrômetros em sentido inverso ao nominal. Portanto, para determinação do volume resultante de ar que é registrado pelo hidrômetro, torna-se importante a avaliação do fluxo de ar em ambos os sentidos.

Como forma de eliminação do ar das tubulações de fornecimento de água, empregam-se alguns dispositivos como a válvula ventosa de dupla função e a válvula ventosa de tríplice função, cuja utilização é recomendada por normas. Leal e Teixeira (2004) avaliaram a eficiência de um eliminador de ar, através de trabalho de campo no município de Juiz de Fora, Minas Gerais. Concluíram que o uso do dispositivo não reduziu significativamente o volume de ar registrado 
pelos hidrômetros utilizados no trabalho. Além disso, verificaram que o uso de eliminadores de ar pode possibilitar contaminação da água, uma vez que esses equipamentos permitem a entrada de ar na rede distribuição de água. Souza et al. (2005), de forma semelhante, avaliaram um dispositivo eliminador de ar, por meio de trabalho de campo na cidade de Campo Grande, Mato Grosso do Sul, e também concluíram que a utilização de eliminador de ar não alterou significativamente as medições de consumo.

Outro equipamento, denominado bloqueador de ar, vem sendo instalado por consumidores de água, visando evitar a cobrança de ar em suas contas. Bloqueador de ar é um dispositivo que, em vez de retirar o ar da tubulação, dificulta a sua passagem no ponto de fornecimento. Ele conta com uma mola interna ligada a um êmbolo, permitindo o escoamento do fluido — ar, água ou ambos - apenas quando a pressão é superior à mínima necessária.

Scalize, Leite e Campos (2015) verificaram a eficiência de um bloqueador de ar através de testes em laboratório. Constataram que, na maioria dos casos, os bloqueadores não interferem no desempenho do hidrômetro, uma vez que não eliminam o ar.

Na maioria dos municípios brasileiros, não há autorização para o uso de dispositivos eliminadores/bloqueadores de ar. Entretanto, alguns entes da Administração Pública já começaram a legislar sobre o tema, como o estado de São Paulo que, através da Lei Estadual n 12.520 de 2 de janeiro de 2007 (SÃO PAULO, 2007), concedeu o direito de aquisição e uso de aparelho eliminador de ar, a ser instalado antes do hidrômetro. Recentemente, o município do Rio de Janeiro, mediante a Lei Municipal n ${ }^{\circ} 6.634$ de 4 de setembro de 2019, também autorizou a instalação de eliminador de ar (RIO DE JANEIRO, 2019). Além disso, a lei estabeleceu que, a partir de sua promulgação, os hidrômetros a serem instalados deverão ter o eliminador instalado conjuntamente no ramal de entrada. No entanto, é preciso levar em consideração a possibilidade de contaminação da água com o uso dos eliminadores de ar.

Os efeitos da presença de ar na medição do consumo de água não é um problema que ocorre apenas no Brasil. Em Porto Rico, o jornal El Nuevo Día apontou a suspeita de que os possíveis volumes de ar presentes nas tubulações de fornecimento de água poderiam estar sendo registrados pelos hidrômetros (KUILAN, 2015).

No Peru, denúncias foram feitas no ano de 2012 contra a Sedapal, empresa de fornecimento de água da capital daquele país, alegando que a entrada de volumes de ar nas tubulações de água fez aumentar consideravelmente os valores cobrados de seus clientes. Apesar disso, a empresa alegou, na época, que os hidrômetros não são capazes de contabilizar os volumes de ar (REDACCÍON PERÚ21, 2012).

Moradores da cidade de Cuernavaca, no México, relataram aumento de $70 \%$ em suas contas de água. Eles suspeitaram de que a entrada de ar ocorreu no enchimento da tubulação de água. Em razão da escassez de água pela qual passou a cidade, o fornecimento de água durante determinado período foi intermitente, fazendo com que, nos esvaziamentos da rede, fosse possível a entrada de volumes de ar. Posteriormente, no enchimento da rede, o ar sairia da rede através dos pontos de consumo de água (SOBERANES, 2017).

\section{Pesquisas anteriores sobre o assunto}

Mello e Farias (2001) realizaram um estudo sobre a quantificação de ar feita pelos hidrômetros. Em laboratório, os referidos autores criaram um sistema com hidrômetros dispostos em diferentes cotas de elevação, que contava com medidores de vazão de escoamento. Foram realizadas medições nos hidrômetros para diferentes vazões, constatando-se que o registro de ar pelo hidrômetro é diretamente proporcional à vazão de escoamento.
Lopes, Lara e Libânio (2011) também realizaram um trabalho sobre o assunto, simulando, em laboratório, uma rede de abastecimento de água, na qual era possível introduzir volumes de ar. A rede possuía dois hidrômetros ligados em série e, entre eles, foram introduzidos em medições diferentes: eliminador de ar, bloqueador de ar e válvula ventosa. Um hidrômetro registrava o volume total de fluido (água e ar) que passava por ele, sendo retirada, logo em seguida, a parcela de ar. Então, um segundo hidrômetro registrava a água que passava por ele. Constataram, entretanto, que a menor vazão se associa ao maior volume de ar aferido, ou seja, apresentam uma relação inversamente proporcional.

Ambos os estudos supracitados basearam-se em redes de escala reduzida criadas em laboratório e contabilizaram o volume de ar ocorrido para diferentes vazões. No entanto, seus resultados quantitativos não podem ser generalizados para redes reais, pois a quantidade de ar incidente é extremamente dependente das características da rede e condições de operação.

Miranda (2011) verificou a influência da presença de ar na macro e micromedição, por meio de testes em laboratório de diferentes medidores: microturbinas, hidrômetros, medidor eletromagnético e turbina intrusiva de seção plena. Os testes foram realizados com e sem a presença de ar, sendo feita uma análise comparativa entre eles. Concluiu que os registros de volumes de ar são proporcionais às vazões, contrariando os resultados obtidos por Lopes, Lara e Libânio (2011), citados anteriormente.

Walter, Mastaller e Klingel (2017; 2018) verificaram, experimentalmente, os erros de medição dos hidrômetros unijato e multijato no processo de enchimento com fluxo bifásico (água e ar). Como resultado dos testes, observaram que até $93 \%$ do volume de ar escoado na tubulação podem ser registrados pelos hidrômetros, evidenciando que o erro de medição é causado principalmente pelo fluxo de ar.

Com o intuito de obter informações que possam contribuir para um maior aprofundamento do estudo deste tema, o presente trabalho buscou verificar o comportamento isolado do hidrômetro perante a presença de ar na tubulação. Para isso, foi feita uma comparação entre o volume de ar escoado e o volume de ar que é efetivamente registrado pelo hidrômetro sob diferentes condições.

Até a presente data, não há uma norma específica ou prática recomendada na literatura sobre procedimentos técnicos para a detecção e quantificação de ar em redes de distribuição de água. Configurando-se como um estudo inicial neste tema, o presente trabalho apresenta também uma metodologia para avaliação quantitativa do escoamento de ar em hidrômetros, permitindo que se verifique a possibilidade de impacto significativo desse fenômeno na medição de consumo em situação real.

\section{Funcionamento do hidrômetro}

Tem-se observado novas tecnologias de hidrometria com alta precisão que já estão disponíveis para uso comercial, como medidores eletromagnéticos e ultrassônicos (TSUTIYA, 2014, p. 214). No entanto, devido ao custo elevado dos referidos equipamentos, os hidrômetros predominantemente utilizados para micromedição, ou seja, para quantificação dos volumes escoados nos pontos de fornecimento, ainda se baseiam em fundamentos estritamente hidráulicos e mecânicos, caracterizados pela incidência de um jato nas pás de uma turbina (Figura 1).

A rotação da turbina está diretamente associada ao volume escoado, ou vazão de entrada, uma vez que esta é função da velocidade $\left(V_{j}\right)$ e da área $\left(A_{j}\right)$ do jato. O giro então é transmitido por meio de um eixo de interligação entre o rotor e a relojoaria, sistema de engrenagens, posicionada logo acima, que faz o registro e a exibição dos parâmetros de medição dos volumes aduzidos. 
Quando há apenas um jato, o hidrômetro é classificado como unijato ou monojato. Essa configuração tende a causar um desequilíbrio de forças na turbina, o que aumenta o atrito no eixo e a instabilidade em elevadas velocidades, contribuindo para o aumento do erro do instrumento.

Para evitar esse efeito, há hidrômetros com orifícios ao redor de uma câmara que provocam a incidência de mais de um jato em diferentes pás da turbina, denominados do tipo multijato (Figura 2). Seu desenho mais sofisticado incorre em custos mais elevados, porém se faz necessário quando é requerida maior precisão ou vazão.

Em ambos os casos (unijato e multijato), para que haja a rotação da turbina, primeiramente, $\mathrm{o}$ atrito deve ser vencido. No cenário da iminência do movimento (regime permanente), a força provocada pelo jato $(F)$, considerado uniforme, em uma pá da turbina pode ser calculada pela simplificação da equação integral da quantidade de movimento linear (Equação 1) (FOX; MCDONALD; PRITCHARD, 2003):

$\vec{F}=\vec{V}_{j} \rho V_{j} \cdot A_{j}$

Tendo em vista a razão entre a massa específica $(\rho)$ da água $\left(1.000 \mathrm{~kg} / \mathrm{m}^{3}\right)$ e do $\operatorname{ar}\left(1,2 \mathrm{~kg} / \mathrm{m}^{3}\right)$, essa equação mostra que, para uma mesma área do orifício do jato $\left(\mathrm{A}_{\mathrm{j}}\right)$, $\mathrm{o}$ ar deve ter uma velocidade $\left(\mathrm{V}_{\mathrm{i}}\right)$ cerca de 800 vezes superior à da água para que consiga superar o atrito.

Portanto, em caso de escoamento de ar no hidrômetro, a vazão mínima para que inicie o giro da turbina e o volume seja contabilizado deverá ser muito superior àquela necessária para que isso ocorra com água. Com base em um raciocínio análogo, em vazões superiores, o volume de ar registrado será sempre inferior ao realmente escoado. Por outro lado, a partir do princípio de funcionamento descrito e da Equação 1, fica evidente a possibilidade de hidrômetros também registrarem ar.

\section{METODOLOGIA}

\section{Aferição dos hidrômetros}

Primeiramente, os hidrômetros utilizados (Tabela 1) foram aferidos em condições normais, ou seja, com escoamento de apenas água no sentido nominal. Esse primeiro teste teve por objetivo avaliar a precisão dos hidrômetros utilizados e, consequentemente, a confiabilidade dos resultados obtidos nos testes

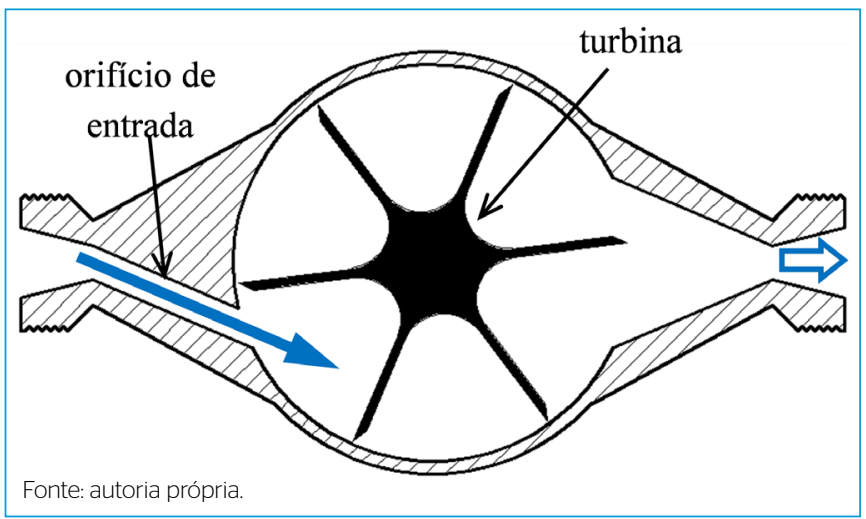

Figura 1 - Representação simplificada de um hidrômetro unijato (vista superior em corte horizontal). posteriores. A bancada hidráulica utilizada para todas as medições realizadas neste trabalho fornece uma vazão máxima de $2.500 \mathrm{~L} / \mathrm{h}$, com pressão hidrostática em torno de 20 m.c.a.

A norma NBR 212:1999 (Medidores velocimétricos de água potável fria até $15 \mathrm{~m}^{3} / \mathrm{h}$ ) da ABNT (1999) e a Portaria no 246 de 17 de outubro de 2000 do Instituto Nacional de Metrologia, Normalização e Qualidade Industrial (INMETRO, 2000) estabelecem as condições que devem satisfazer os hidrômetros para água fria, assim como premissas para o teste de aferição. Em ambos os documentos citados, são determinados erros de 10 ou 5\%, de acordo com a vazão e a classificação do hidrômetro (Tabela 2).

O procedimento adotado consiste, basicamente, em comparar os volumes registrados pelos hidrômetros com a medição feita por um galão com capacidade de 100 L, certificado pelo INMETRO (Figura 3). O registro de gaveta R2 é ajustado para aproximar a vazão escoada aos valores desejados (Tabela 2), dentro de uma tolerância definida pelas normas referenciadas. Um medidor de vazão (rotâmetro) é utilizado para facilitar esse processo, no entanto, a vazão é, efetivamente, verificada através da divisão do volume registrado no galão pelo tempo cronometrado.

Caso esse resultado não se adeque à tolerância, o teste é repetido, reajustando-se o registro R2. Ao final de cada teste, o registro de esfera R3 é aberto para drenar a água acumulada no reservatório (galão). Em seguida, através de um sistema envolvendo cisterna, bomba e um reservatório elevado, essa água é reaproveitada para novos testes.

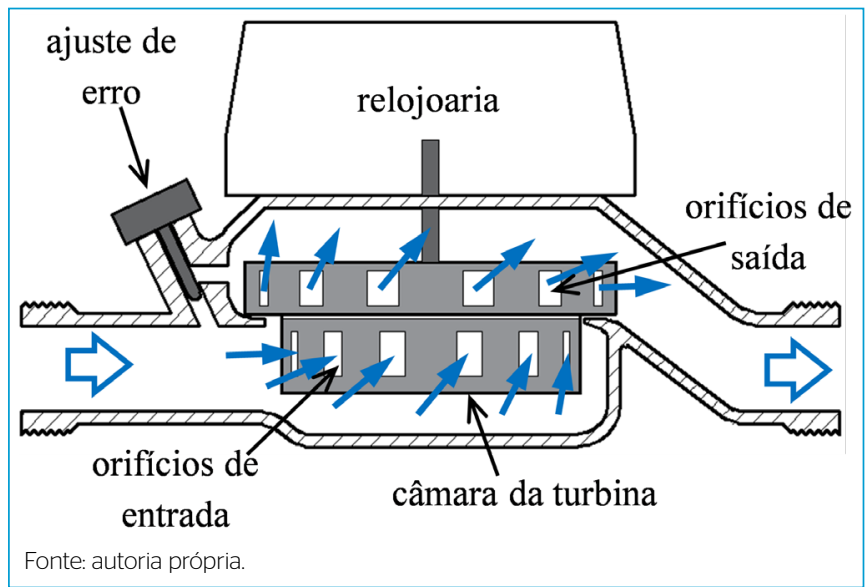

Figura 2 - Representação simplificada de um hidrômetro multijato (vista latera em corte vertical).

Tabela 1 - Hidrômetros utilizados na realização dos testes.

\begin{tabular}{l|c|c|c|c|c} 
Hidrômetro & Tipo & Classe & N $^{\circ}$ de série & Fabricante & $\begin{array}{c}\text { Ano de } \\
\text { fabricação }\end{array}$ \\
\hline HD-1 & Multijato & B & AO4M005112 & ENERGYRUS & 2004 \\
\hline HD-2 & Multijato & B & A12L266917 & LAO & 2012 \\
\hline HD-3 & Unijato & B & A18G004433 & SAGA & 2018 \\
\hline
\end{tabular}

Tabela 2 - Erro máximo admissível para cada vazão.

\begin{tabular}{l|c|c|c} 
Vazão & $\begin{array}{c}\text { Mínima } \\
30 \mathrm{~L} / \mathrm{h}\end{array}$ & $\begin{array}{c}\text { Transição } \\
120 \mathrm{~L} / \mathrm{h}\end{array}$ & $\begin{array}{c}\text { Máxima } \\
1.500 \mathrm{~L} / \mathrm{h}\end{array}$ \\
\hline Erro máximo admissível & $10 \%$ & $5 \%$ & $5 \%$ \\
\hline
\end{tabular}

Fonte: NBR 212:1999 (ABNT, 1999) e Portaria INMETRO n 246/2000 (INMETRO, 2000). 
A diferença das leituras volumétricas iniciais e finais do hidrômetro em cada teste, denominada de volume medido $\left(V_{\text {med }}\right)$, é então comparada com o volume acumulado no reservatório, denominado de volume do galão $\left(V_{\text {gal }}\right)$, sendo o erro assim determinado expresso pela Equação 2:

erro $=\frac{V_{\text {med }}-V_{\text {gal }}}{V_{\text {gal }}} \times 100 \%$

Para cada vazão (mínima, transição e máxima), o procedimento é realizado três vezes, adotando-se então o erro médio. Os erros obtidos nos testes com três hidrômetros em três vazões diferentes são pequenos (Tabela 3) e atendem às condições exigidas pela Portaria INMETRO nº 246/2000 (Tabela 2).

\section{Medição do volume de ar com fluxo no sentido nominal}

Ao contrário da aferição de hidrômetros para medição de água, não há um procedimento consolidado na literatura para avaliação do efeito de ar no valor registrado. Foi elaborado um procedimento com o intuito de quantificar o volume de ar escoado que é, efetivamente, registrado pelo hidrômetro (Figura 4). Para isso, um reservatório de ar foi utilizado, cujo volume útil fora previamente quantificado em $55,5 \mathrm{~L}$.
Nessa montagem, o fluxo seguiu o mesmo sentido daquele indicado no hidrômetro. O sistema foi formado por um registro que regulava a vazão em estudo (R2) pelo reservatório de ar, por uma válvula ventosa (VV) e pelo hidrômetro (já aferido anteriormente).

Conforme a água adentrava o reservatório pela tubulação oriunda da caixa d'água, o ar escoava pelo tubo de saída, passando pelo hidrômetro. Durante esse processo, o registro R3 (dreno) permanecia fechado, fazendo com que a taxa de escoamento de saída de ar fosse a mesma da entrada de água. A válvula ventosa serviu como interrupção do escoamento, uma vez que ela impede a passagem

Tabela 3 - Aferição no sentido nominal do escoamento.

\begin{tabular}{l|c|c|c}
\multicolumn{4}{c}{ Erros médios dos hidrômetros (\%) } \\
\hline \multirow{2}{*}{ Vazão } & Mínima & Transição & Máxima \\
\cline { 2 - 4 } & $30 \mathrm{~L} / \mathrm{h}$ & $120 \mathrm{~L} / \mathrm{h}$ & $1.500 \mathrm{~L} / \mathrm{h}$ \\
\hline \multirow{2}{*}{ HD1 } & 1,37 & 2,66 & 3,25 \\
\hline HD2 & 2,08 & $-0,23$ & 0,63 \\
\hline HD3 & 5,44 & $-0,03$ & 0,16 \\
\hline
\end{tabular}

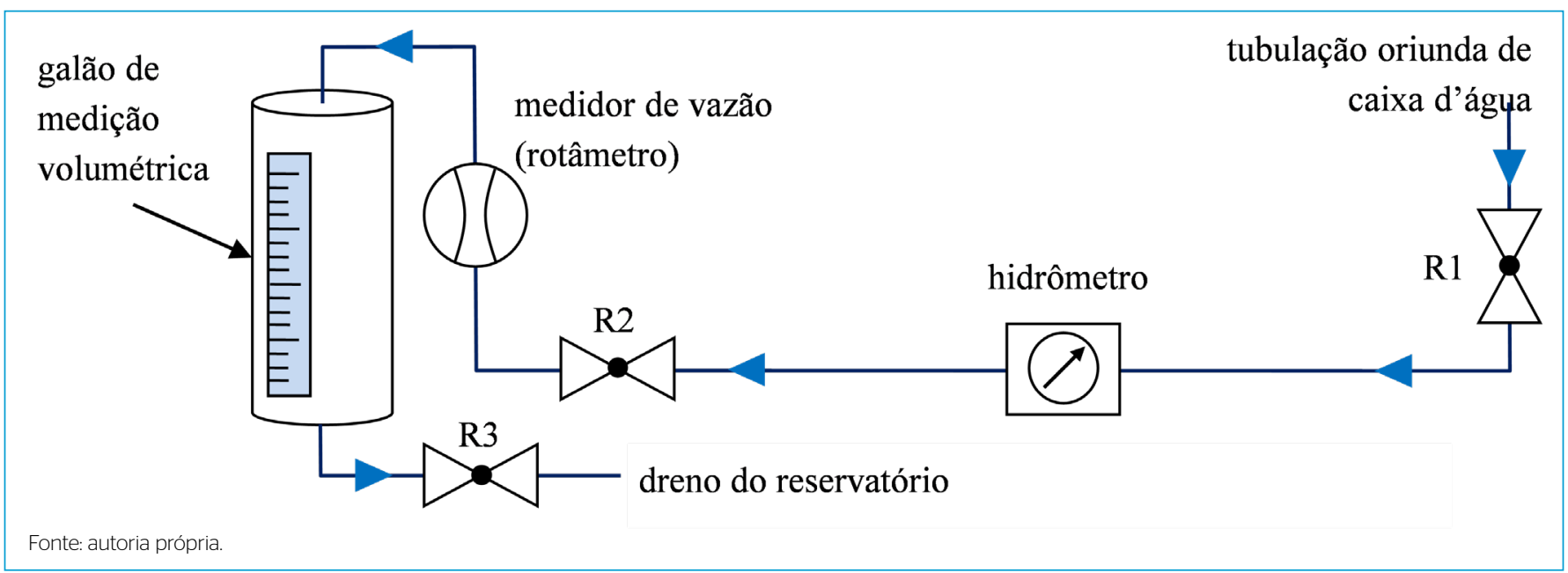

Figura 3 - Esquema para aferição dos hidrômetros (apenas água).

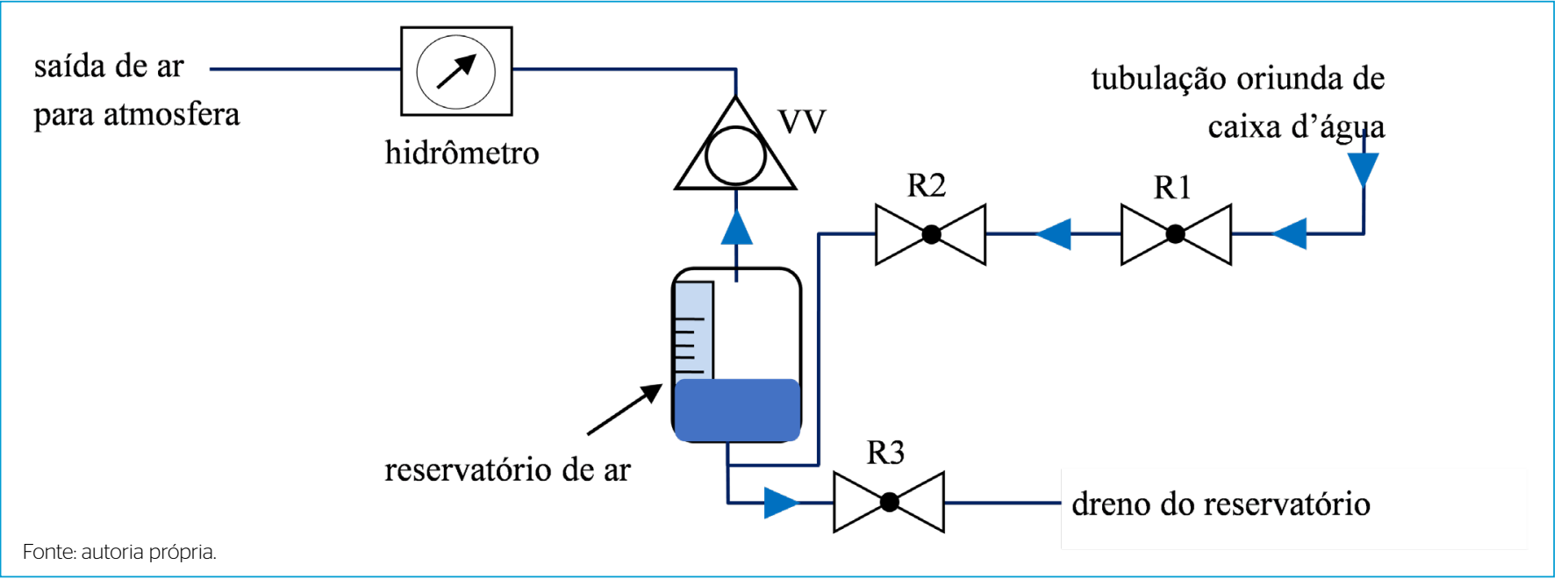

Figura 4 - Esquema do aparato proposto para medição do volume de ar. 
de água. Dessa forma, no momento em que o reservatório era completamente cheio de água, o volume de ar havia sido totalmente escoado e, consequentemente, o hidrômetro já havia registrado as frações de ar correspondentes.

Ao final de cada medição, o registro R3 era então aberto, e a água utilizada para encher o reservatório era drenada e bombeada de volta para a caixa d'água.

O aparato proposto para medição de ar (Figura 5A) também conta com uma mangueira transparente a fim de possibilitar a visualização do nível d’água dentro do reservatório. As fotos da Figura $5 \mathrm{~B}$ e da $5 \mathrm{C}$ mostram os detalhes das conexões na parte superior e na inferior respectivamente.

\section{Medição do volume de ar com fluxo no sentido inverso}

Para avaliação da medição de ar no sentido inverso, foi adotado o mesmo procedimento anterior, porém com o hidrômetro em posição invertida. Dessa forma, o ar foi escoado no sentido inverso ao sentido indicado no hidrômetro, ocasionando uma "desmarcação" nele, ou seja, seus ponteiros giraram no sentido anti-horário, fazendo com que o volume registrado fosse menor a cada medição.

\section{RESULTADOS E DISCUSSÃO}

Os volumes de ar registrados pelos hidrômetros são apresentados na Figura 6 para as diferentes vazões aplicadas no sentido nominal. Observa-se que, para pequenas vazões (inferiores a $430 \mathrm{~L} / \mathrm{h}$ ), os volumes registrados pelos hidrômetros são nulos, porém, à medida que as vazões aumentam, o volume de ar registrado também aumenta significativamente. Além disso, nesse sentido de escoamento, as curvas dos três hidrômetros testados apresentam característica similar

Quando o fluxo de ar ocorre em sentido inverso, as porcentagens de volume registrado são menores (Figura 7). Nesse caso, há registro nulo nos hidrômetros HD-1 e HD-2 para vazões até 780 L/h e no hidrômetro HD-3 para vazões até $750 \mathrm{~L} / \mathrm{h}$. Observa-se uma divergência entre curvas dos diferentes hidrômetros. Enquanto o hidrômetro HD-1 registra 37\% na vazão máxima, o hidrômetro HD-2 contabiliza 70\% e o hidrômetro HD-3, 66\%.

Observa-se que a vazão mínima para que volumes de ar sejam contabilizados é bastante superior àquela necessária para que se contabilize volumes de água (Tabela 3), tanto no sentido nominal (Figura 6) quanto no inverso (Figura 7), e o volume de ar medido foi sempre inferior ao efetivamente escoado. Percebe-se também um salto no valor medido pelo hidrômetro HD-3 na vazão invertida de $815 \mathrm{~L} / \mathrm{h}$, mais acentuado que o observado nos demais. Esse comportamento diferenciado pode ser explicado pelo fato desse hidrômetro ser do tipo unijato, enquanto os demais são do tipo multijato (Tabela 1).

O volume de ar registrado depende do sentido e da vazão de escoamento. No sentido nominal, há um maior registro de ar, chegando a $87 \%$ para uma vazão de $1.650 \mathrm{~L} / \mathrm{h}$ e a $90 \%$ numa vazão de $3.100 \mathrm{~L} / \mathrm{h}$, confirmando as verificações feitas por Miranda
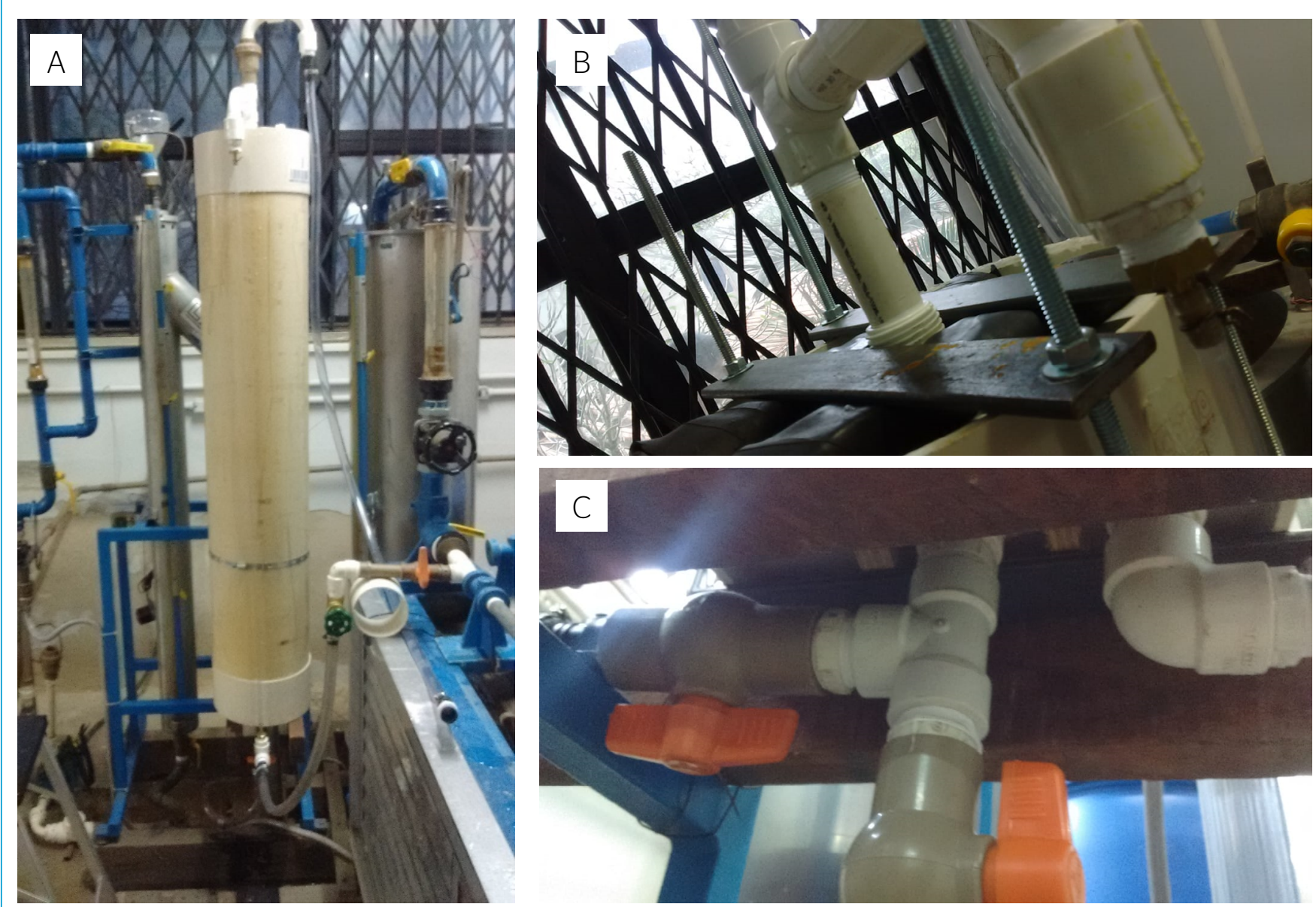

Fonte: autoria própria

Figura 5 - (A) Aparato proposto para medição de ar, (B) detalhe das conexões na parte superior e (C) detalhe das conexões na parte inferior. 


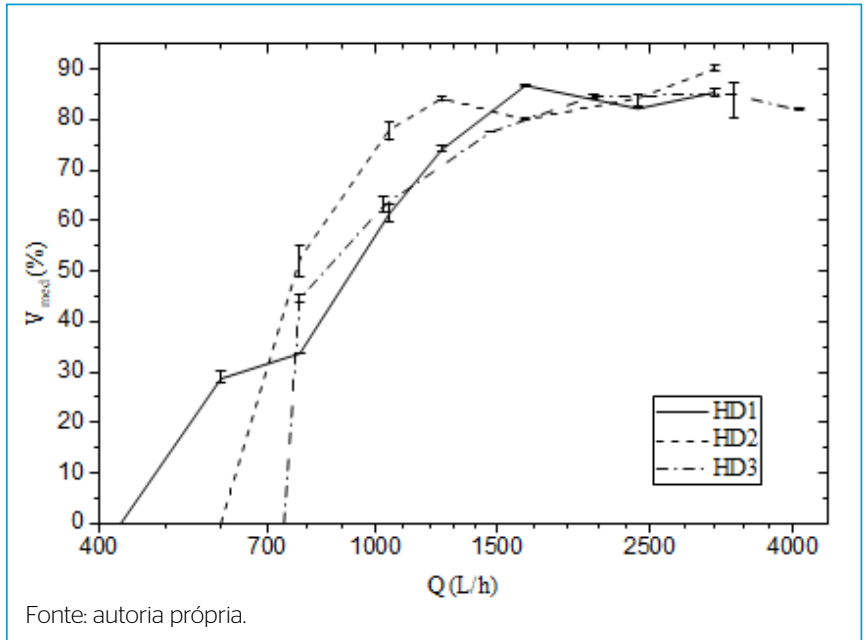

Figura 6 - Volume de ar medido $V_{\text {med }}$ (\%) versus vazão $Q$ - sentido nominal.

(2011) e por Walter, Mateller e Klingel (2018) de que o volume de ar contabilizado pelos hidrômetros corresponde a 82 e $93 \%$, respectivamente. No entanto, para vazões inferiores a $430 \mathrm{~L} / \mathrm{h}$, a parcela de ar registrada é nula. Traduzindo-se para um cenário real, a sobremedição pode ser elevada, porém, se o enchimento da rede de abastecimento provoca vazões de ar relativamente baixas, a sobremedição não será perceptível.

Em ambos os sentidos (nominal e inverso), observa-se que o volume de ar registrado pelos hidrômetros cresce na medida em que há um aumento da vazão, fato que corrobora a conclusão feita por Mello e Farias (2001) de que há uma relação direta entre essas variáveis. Entretanto, diverge dos resultados obtidos por Lopes, Lara e Libânio (2011), os quais indicaram uma relação inversa.

\section{CONCLUSÕES}

Os testes realizados mostram que, efetivamente, os hidrômetros também registram um volume do ar que, eventualmente, escoa na tubulação, acarretando sobremedição do consumo de água. Os resultados foram compatíveis com a análise previamente realizada com base no funcionamento desses dispositivos e também com conclusões de outros autores.

$\mathrm{O}$ volume de ar registrado depende do sentido e da vazão de escoamento. No sentido nominal, há um maior registro de ar, chegando a $90 \%$ numa vazão de $3.100 \mathrm{~L} / \mathrm{h}$. No entanto, para vazões inferiores a $430 \mathrm{~L} / \mathrm{h}$, a parcela de ar registrada é nula. No sentido inverso (contrário ao nominal), a vazão mínima para que o ar seja contabilizado é de cerca de $750 \mathrm{~L} / \mathrm{h}$ e os hidrômetros registram um volume

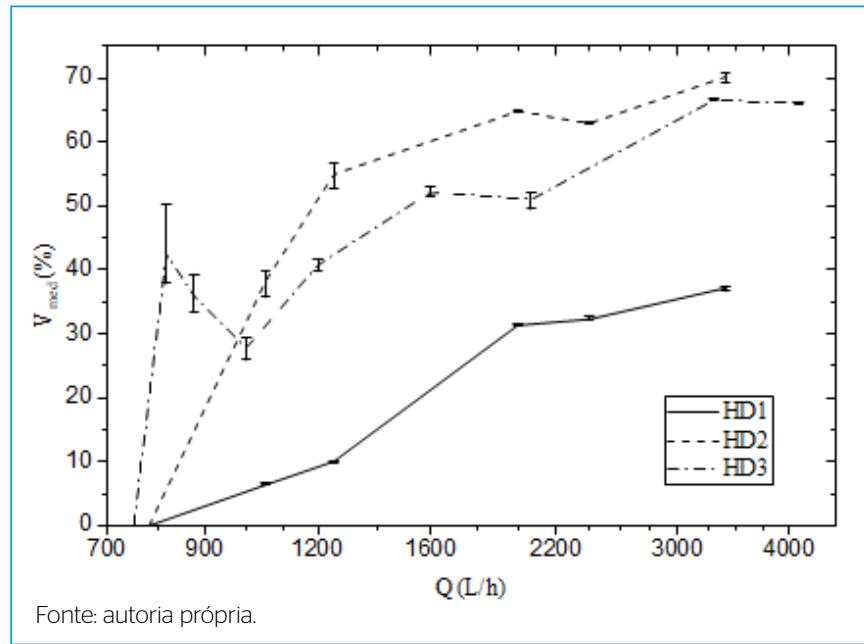

Figura 7 - Volume de ar medido $V_{\text {med }}(\%)$ versus vazão $Q$ - sentido inverso.

menor que o medido no sentido nominal para todas as vazões avaliadas. No escoamento monofásico, verificado no presente trabalho, o percentual máximo de ar registrado é próximo ao constatado no escoamento bifásico por outros autores.

Uma vez que as redes de distribuição de água passam por operações de enchimento e esvaziamento, isso pode acarretar a passagem de ar pelos hidrômetros em ambos os sentidos (nominal e inverso). No entanto, a quantidade de ar contabilizada durante o enchimento da rede não será integralmente descontada durante o esvaziamento, uma vez constatado que o hidrômetro mede uma parcela menor do volume de ar escoado no sentido inverso. Além disso, a vazão da rede durante o enchimento é maior que a de esvaziamento, ampliando essa diferença entre volume de ar contabilizado e descontado.

Por fim, o trabalho desenvolvido mostra que, para identificar se há condições para sobremedição do consumo de água em um determinado local, é necessário avaliar a vazão de ar nos pontos de fornecimento durante o enchimento. Caso realmente ocorra, uma maneira prática de evitá-la é realizar um enchimento mais lento e controlado da rede. Outra opção seria o desenvolvimento de hidrômetros capazes de registrar volumes de ar em ambos os sentidos de escoamento com a mesma precisão ou que não contabilizem nenhum volume de ar.

\section{CONTRIBUIÇÕES DOS AUTORES}

Tavares, W. A.: Curadoria de Dados, Escrita — Primeira Redação. Nascimento, E. A.: Análise Formal, Escrita - Revisão e Edição. Nascimento, G. C.: Conceituação, Supervisão

\section{REFERÊNCIAS}

ASSOCIAÇÃO BRASILEIRA DE NORMAS TÉCNICAS (ABNT). NBR 12218: Projeto de rede de distribuição de água para abastecimento público. Rio de Janeiro: ABNT, 1994. 4 p.

ASSOCIAÇÃO BRASILEIRA DE NORMAS TÉCNICAS (ABNT). NBR NM 212: Medidores velocimétricos de água potável fria até $15 \mathrm{~m}^{3} / \mathrm{h}$. Rio de Janeiro: ABNT, 1999. 19 p.
BRASIL. Lei Federal n 9.433, de 8 de janeiro de 1997. Institui a Política Nacional de Recursos Hídricos, cria o Sistema Nacional de Gerenciamento de Recursos Hídricos, regulamenta o inciso XIX do art. 21 da Constituição Federal e altera o art. 10 da Lei no 8.001, de 13 de março de 1990, que modificou a Lei no 7.990, de 28 de dezembro de 1989. Diário Oficial [da] República Federativa do Brasil, Brasília, 8 jan. 1997. 
COMPANHIA ESTADUAL DE ÁGUAS E ESGOTOS DO RIO DE JANEIRO (CEDAE). A Cedae - História - Origem. Disponível em: http://www.cedae. com.br/origem. Acesso em: 21 jun. 2018.

FONSECA, A.D.F.C.; PRADO FILHO, J.F.D. Ouro Preto, Água Limpa: O abastecimento doméstico de água no epicentro do ciclo do ouro. Revista Brasileira de Recursos Hidricos, v. 13, n. 3, p. 177-188, 2008. https://doi. org/10.21168/rbrh.v13n3.p177-188

FOX, R.W.; MCDONALD, A.T.; PRITCHARD, P.J. Introduction to Fluid Mechanics. 6 a ed. [s...]: Wiley, 2003.

INSTITUTO NACIONAL DE METROLOGIA, NORMALIZAÇÃO E QUALIDADE INDUSTRIAL (INMETRO). Regulamento técnico metrológico a que se refere a portaria INMETRO no 246 de 17 de outubro de 2000. Brasil: INMETRO, 2000.

KUILAN, G.R. AAA cobra por aire em las tuberías. El Nuevo Dia, Porto Rico, 28 maio 2015. Disponível em: https://www.elnuevodia.com/noticias/locales/ nota/aaacobra poraireenlastuberias-2052872/. Acesso em: 27 jun. 2018.

LEAL, F.C.T.; TEIXEIRA, J.C. Avaliação da eficácia e da possibilidade da contaminação da água em eliminadores de ar fabricados em polipropileno, quando instalados em cavaletes de ligações de água potável - estudo de caso: Juiz de Fora - MG. Revista de Engenharia Sanitária e Ambiental, v. 9, n. 3. p. 187-192, set. 2004. https://doi.org/10.1590/S1413-41522004000300003

LEAL, F.C.T; TEIXEIRA, J.C. O ar nas contas de água. Revista de Engenharia Sanitária e Ambiental, v. 6, n. 3-4, p. 96-97, 2001.

LOPES, N.P.; LARA, M.; LIBÂNIO, M. Quantificação em escala de bancada do volume de ar em ligações prediais de água. Revista de Engenharia Sanitária e Ambiental, v. 16, n. 4, out.-dez. 2011. https://doi.org/10.1590/S141341522011000400005

MACINTYRE, A.J. Instalações Hidráulicas: prediais e industriais. 4a ed. Rio de Janeiro: LTC, 2013.579 p.

MELLO, E.J.; FARIAS, R.L. O ar e a sua influência na medição do consumo de água. In: CONGRESSO BRASILEIRO DE ENGENHARIA SANITARIA E AMBIENTAL, 21., 2001. Anais [...]. João Pessoa: Abes, 2001.

MIRANDA, I.S.L. Presença de ar no Sistema de Abastecimento de Água: influências na macro e micromedição. Trabalho de Conclusão de Curso (Graduação) - Departamento de Engenharia Civil da Universidade Federal do Rio Grande do Sul, Porto Alegre, 2011. 88 p.

PEREIRA, L.G.; ILHA, M.S.O. Avaliação da submedição de água em edificações residenciais de interesse social localizadas em Campinas. Ambiente Construído, Porto Alegre, v. 8, n. 2, p. 7-21, 2008.

PORTO, R.M. Hidráulica básica. 4ª ed. São Carlos: EESC USP, 2006.540 p.

REDACCIÓN PERÚ21. El colmo: Sedapal cobra por el aire que corre por las tuberías. Perú 21, 2012. Disponível em: https://peru21.pe/lima/colmosedapal-cobra-aire-corre-tuberias-12899. Acesso em: 27 jun. 2018.
RIO DE JANEIRO. Lei Municipal n 6.634, de 4 de setembro de 2019. Dispõe sobre a permissão da instalação de equipamento eliminador/purgador de ar da tubulação do sistema de abastecimento de água no ramal de entrada de residência, comércio, serviço ou indústria. Diário Oficial do Município do Rio de Janeiro, Rio de Janeiro, 5 set. 2019.

SANCHEZ, J.G.; MOTTA, A.S.; ALVES, W.C. Estimativa de volume de água não medido em ligações residenciais por perda de exatidão nos hidrômetros, na cidade de Juazeiro - BA. In: CONGRESSO INTERAMERICANO DE ENGENHARIA SANITARIA E AMBIENTAL, 27., 2000. Anais [...]. Porto Alegre: Abes, 2000.

SÃO PAULO. Lei Estadual no 12.520, de 2 de janeiro de 2007. Disciplina a instalação de aparelho eliminador de ar em unidades servidas por ligação de água e esgoto, e dá outras providências. Diário Oficial do Estado de São Paulo, São Paulo, 3 jan. 2007.

SCALIZE, P.S.; LEITE, W.C.A. Variação na micromedição do consumo de água no funcionamento correto e reversível do hidrômetro. Revista Eletrônica de Engenharia Civil, v. 6, n. 1, p. 9-15, 2013. https://doi.org/10.5216/ reec.v6i1.21240

SCALIZE, P.S:; LEITE, W.C.A.; CAMPOS, M.A.S. Influência da válvula bloqueadora de ar instalada após o hidrômetro. Universitas, Araçatuba, v. 7. p. 135-147, 2015

SOBERANES, C. Se excede SAPAC em cobros por aire em las tuberías Diario de Morelos, Cuernavaca, 24 jun. 2017. Disponível em: https://www. diariodemorelos.com/noticias/se-excede-sapac-en-cobros-por-aire-en-lastuber\%C3\%ADas. Acesso em: 27 jun. 2018.

SOUZA, R.S.D.; POLIZER, M.; RONDON, M.A.C.; VAL, L.A.A.D.; GONDA, J. Avaliação da influência de um equipamento eliminador de ar na medição de consumo de água numa rede de distribuição. In: CONGRESSO BRASILEIRO DE ENGENHARIA SANITARIA E AMBIENTAL, 23., 2005. Anais [.... Campo Grande: Abes, 2005. 11 p.

TAVARES, W.A.; NASCIMENTO, E.A.; NASCIMENTO, G.C. Sistema de medição de ar em pontos de abastecimento de águas. In: WORKSHOP DE ENGENHARIA DE BIOSSISTEMAS, 4., 2018. Anais [...]. Niterói: Agrah Consultoria, 2018. 284 p.

TSUTIYA, M.T. Abastecimento de água. $4^{a}$ ed. São Paulo: Departamento de Engenharia Hidráulica e Sanitária da Escola Politécnica da Universidade de São Paulo, 2014. 643 p.

WALTER, D.; MASTALLER, M.; KLINGEL, P. Accuracy of single-jet and multijet water meters under the influence of the filling process in intermittently operated pipe networks. Water Science and Technology: Water Supply, v. 18, n. 2, p. 679-687, 2018. https://doi.org/10.2166/ws.2017.149

WALTER, D.; MASTALLER, M.; KLINGEL, P. Accuracy of single-jet water meters during filling of the pipe network in intermittent water supply. Urban Water Journal, v. 14, n. 10, p. 991-998, 2017. https://doi.org/10.1080/157306 2X.2017.1301505 